\title{
TUBERCULOUS APPENDICITIS
}

\section{(A Case Report)}

\section{Lt Col PK HOTA* , Lt Col GS MISRA*, Sqn Ldr SIVARAMAKRISHNA ${ }^{+}$, Lt Col GU DESHPANDE ${ }^{\#}$}

\author{
MJAFI 1998; $54:$ 69-70
}

KEYWORDS : Appendicitis; Tuberculosis.

\section{Introduction}

Tuberculosis presenting as appendicitis is uncommon. Tuberculous appendicitis was first mentioned in literature in 1837 [1]. Many authors have subsequently also described the same. However, an analysis of appendicectomies done at various hospitals report an incidence of only 1 to 3 per cent of all appendicectomies. In known cases of tuberculosis, the incidence may however be 24 to 30 per cent [2]. Even a recent report from Kenya reports only one case out of 348 appendicectomies [3].

We present one such case, which was encounteredas an emergency appendicectomy.

\section{Case Report}

A 27-year-old airman, a known case of pulmonary tuberculosis, on antitubercular treatment (EHRZ) wef 19 May 96 was admitted to our hospital on 5 Jun 96 with colicky pain lower abdomen of 2 days duration and constipation, vomiting and low grade fever of one day duration.

The pain was of sudden onset, initially in the periumbilical and epigastric region and later localised to the right iliac fossa. On the second day he developed low grade continuous fever, associated with vomitting. He was constipated though he was occasionally passing flatus. He gave no past similar history.

On examination he was found to be an averagely built, well nourished individual, in pain. There was no pallor or lymphadenopathy. Vital parameters were within normal limits. The abdomen was not distended. There was marked guarding and rigidity over the right iliac fossa with marked tenderness over the McBurney's point. There was no palpable mass or ascitis. Bowel sounds were normal. A per rectal examination revealed no abnormality. Other systemic examination was within normal limits.

He was diagnosed as a case of acute appendicitis and was scheduled for an emergency appendicectomy.

Routine hemogram revealed mild anaemia $(\mathrm{Hb} 10.1 \mathrm{gm} / \mathrm{dL})$ with leucocytosis (TLC $10600 / \mathrm{cmm}$ and polymorphs $84 \%$ ). Urinalysis did not show any abnormalities.

He was operated upon the same evening. Approach was through a grid iron incision which was converted to a muscle cutting incision due to difficulty in getting at the appendix.

The appendix was short ( $4 \mathrm{~cm}$ long), thick, turgid and was pelvic in position. There was purulent peritoneal fluid localized to the periappendiceal region. There were adhesions but no mass had formed in the ileocaecal region. There was no mesenteric lymphadenitis. Appendicectomy was done in the usual way and abdomen closed without a drain.

Post operatively EHRZ was continued. He made an uneventful recovery.

Gross examination of the specimen revealed marked congestion of the external surface with an obliterated lumen.

The microscopical features (depicted in Fig $1 \& 2$ ), show multiple granulomas in submucosa predominantly, with a few granulomas in muscle layers. The granulomas were composed epitheloid cells, Langhans giant cells and lymphocytes. A few granulomas showed caeseation. The muscle layer showed diffuse infiltration of mononuclear cells. No acid fast bacilli could be demonstrated.

\section{Discussion}

Though acute appendicitis is one of the commonest emergencies encountered in surgical practice, tuberculous appendicitis is rare. Since the first case was reported in 1837 by Corbin, about 300 cases have been reported in literature [1]. Most authors have documented a slightly greater incidence among females than males, with a wide variation in age.

Tuberculous appendicitis presents in three ways. The first is as a chronic disease process, presenting with low grade pain abdomen, occasional vomiting with diarrhoea and with findings of tenderness and a mass in the right iliac fossa. The second type is with features of a classical acute appendicitis. The third type is an incidental discovery, the appendix having been removed for a different cause [4]. Our patient presented with features of the second type.

Isolated infection of the appendix with tuberculosis is rare. Curiously, though the ileocaecal area is commonly a seat of tuberculosis, the appendix is rarely

${ }^{*}$ Classified Speciaiist (Surgery), ${ }^{+}$Surgeon Trainee, Command Hospital (SC); ${ }^{\#}$ Reader, Dept of Pathology, Armed Forces Medical College, Pune 411040 


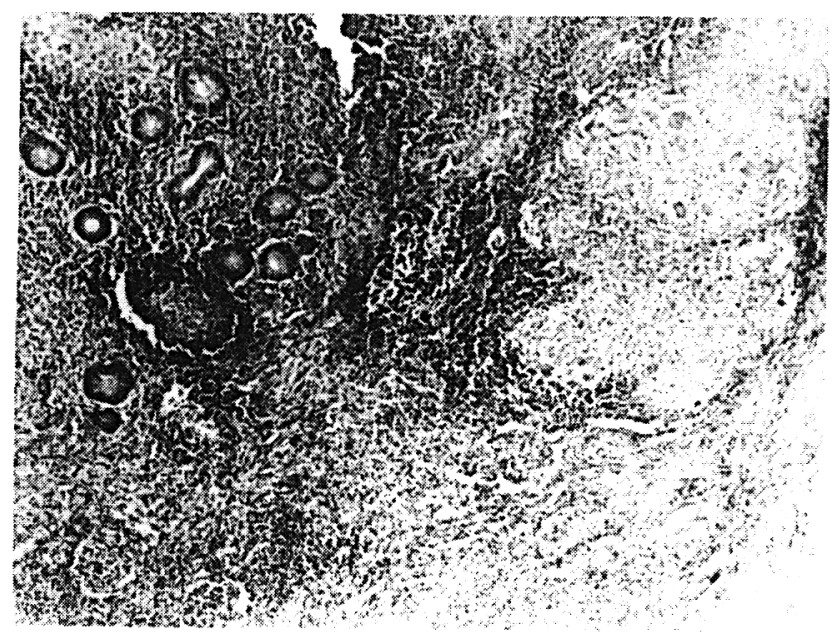

Fig. 1: Shows mucosal glands of the appendix and granulomas in left hand corner.

involved. Anand in his record of 50 hemicolectomies for hypertrophic ileocaecal tuberculosis did not find the appendix involved in even one case. In pelvic tuberculosis [5]. Brown et al have shown an incidence of 2 per cent of appendicular involvement [6]. In our case, the appendix was possibly secondarily infected because of pulmonary tuberculosis.

Postulated routes of infection are by direct spread from neighbouring organs, from ingested infected food or via blood stream from a distant focus.

Pathologically two varieties are seen : the ulcerative form which is commoner, or the hyperplastic variety. The former variety was seen in our patient.

The diagnosis of tuberculous appendicitis on clinical grounds is difficult. Patel et al had performed a right hemicolectomy suspecting ileocaecal tuberculosis though it later turned out that the caecum was disease free. Only the appendix was involved histologically [1]. Even Patkin and Robinson performed a caecotomy in one case suspecting carcinoma [7].

However, the treatment of this condition is appendicectomy only. Though surgery alone cures isolated

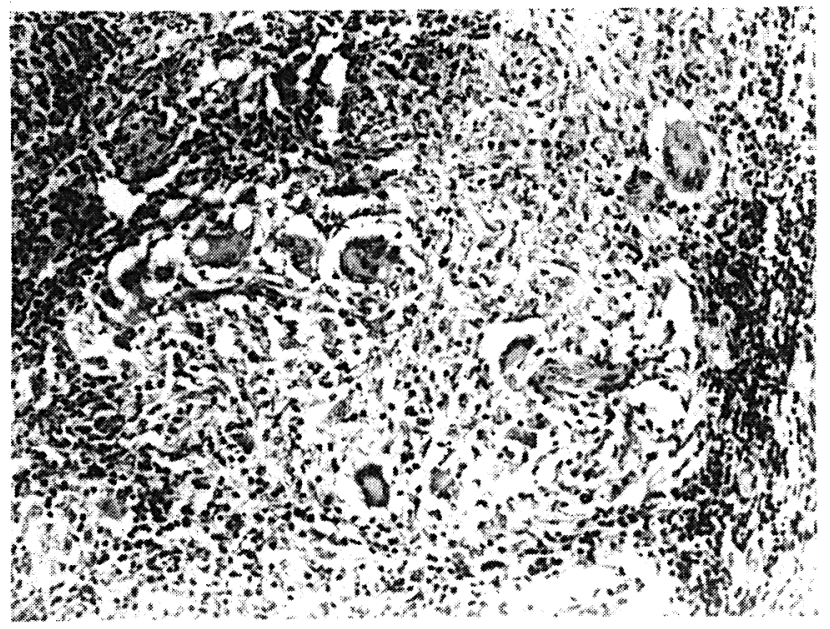

Fig. 2: Shows granulomas with minimal caseation.

tuberculosis of the appendix, in cases of secondary involvement or an uncertain primary source, a full course of antituberculous treatment is recommended.

\section{REFERENCES}

1. Patel PA. Tuberculous Appendicitis. Brit J Clin Pract 1975; 29: $87-90$.

2. Morrison H, Mixter CG, Schlesinger MJ, Ober WB. Tuberculosis localized in the vermiform appendix. $N$ Engl J Med 1952; 246: 329-32.

3. Kakande I, Nehra MK. Appendicectomy in Consolata Hospital, Nyeri: Analysis of operative and histological findings. East Afr Med J (Kenya) 1990; 67: 573-7.

4. Singh MK, Alunabh V and Kapoor VK. Tuberculosis of the appendix-A report of 17 cases and a suggested aetiopathological classification. Postgrad Med J 1987; 63: 855-7.

5. Anand SS. Hypertrophic ileocaecal tuberculosis in India with a record of fifty hemicolectomies. Ann Roy Coll Surg 1956; 19: 205-22.

6. Brown AB, Gilbert CRA, TeLinde RW. Pelvic tuberculosis. Obstet Gynaecol 1953; 2: 476-83.

7. Patkin M, Robinson BL. Tuberculosis of the Appendix. Brit J Clin Pract 1964; 18: 741-2. 